\title{
Bissregistrierung auf höchstem Niveau
}

Eine präzise Bissnahme ist ein entscheidender Faktor im Rahmen von prothetischen Versorgungen. Federnde Materialien können hierbei zu unangenehmen Bisserhöhungen führen. Um das zu vermeiden bietet Zhermack nun ein neues, extrahartes Bissregistrat.Während die meisten anderen Bissregistrate auf A-Silikon basieren ist das neue Acrybite ein Material auf Bis-

Acrylat

Basis. Das ermöglicht eine von A-Silikonen nicht zu erreichende Härte von über 70 Shore D, bzw. 30 Barcol, was Acrybite zum derzeit härtesten Bissregistrat auf dem Markt macht. Neben der Bissnahme eignet es sich auch zur Befestigung von Abformpfosten oder Transferkäppchen bei Implantatabformungen. Es sorgt für festsitzende Abformpfosten, die sich auch unter Druck nicht bewegen oder verschieben.

Das Material verhindert durch hohe Standfestigkeit ein Zerfließen in die Interdentalräume und bildet einen hohen Kontrast durch die blaue Farbe. Eine leichte Fräsbarkeit ohne spröde oder brüchig zu sein erleichtert die Weiterverarbeitung.

Nach einer Pressemitteilung der Zhermack GmbH Deutschland, Marl am Dümmer www.zhermack.de 